\title{
A Numerical Study of Three-Dimensional Gravity Waves Triggered by Deep Tropical Convection and Their Role in the Dynamics of the QBO
}

\author{
C. Piani,* D. Durran, M. J. Alexander, + and J. R. Holton \\ Department of Atmospheric Sciences, University of Washington, Seattle, Washington
}

(Manuscript received 26 August 1999, in final form 31 January 2000)

\section{ABSTRACT}

\begin{abstract}
A 3D mesoscale model is used to study the structure of convectively triggered gravity waves in the Tropics and their role in the dynamics of the middle atmosphere. Simulations with three stratospheric background zonal wind cases are examined. In the first case the background wind profile is constant; the other two are representative of the easterly and westerly phases of the quasi-biennial oscillation (QBO). Spectral analysis is used to link the structure of the triggered gravity waves to the dominant vertical wavelength of the latent heating within the convection.

In the QBO-wind shear cases, upward propagating gravity waves are damped as they approach their critical layer. The signature of critical-layer absorption is clearly visible in the profiles of vertical momentum-flux divergence. In the simulations with open boundary conditions, the response to vertical momentum-flux divergence takes the form of large dynamic pressure differences between the east and west boundaries together with accelerations in the mean zonal wind. To capture the mean-flow accelerations that occur in response to vertical momentum-flux divergence in a horizontally periodic domain such as the earth's atmosphere, the simulations were repeated in a domain with periodic lateral boundaries. In these simulations, the mean-flow acceleration is almost entirely balanced by gravity wave momentum-flux divergence while all other terms are virtually null.

Quantitative analysis of the simulated stratospheric response to gravity wave momentum-flux divergence is used, together with statistics of mesoscale convective systems, to estimate the average forcing caused by convectively generated gravity waves in the lower stratosphere and their role in the dynamics of the QBO.
\end{abstract}

\section{Introduction}

In the northern midlatitudes, stably stratified flow over topography is generally considered the most important source of gravity waves (McFarlane 1987). In the Tropics, however, deep convection could play a more important role.

Tropical and midlatitude dynamics differ from more than one standpoint. The primary source of energy in the midlatitudes is the available potential energy associated with the meridional temperature gradient. By comparison, the thermal gradient is very small in the Tropics, and the primary energy source appears to be latent heat released in association with convective cloud systems. The presence of extended bands of convection

\footnotetext{
* Current affiliation: Atmospheric Oceanic and Planetary Physics, Clarendon Laboratory, Oxford University, Oxford, United Kingdom.

+ Current affiliation: Colorado Research Associates Division, Northwest Research Associates, Inc., Boulder, Colorado.
}

Corresponding author address: Dr. C. Piani, Atmospheric Oceanic and Planetary Physics, Clarendon Laboratory, Oxford University, Parks Road, Oxford OX1 3PU, United Kingdom. E-mail: cpiani@atm.ox.ac.uk together with a smaller ratio of landmass versus oceans, at least compared with the northern midlatitudes, could shift the preferred source of gravity waves from topography to deep convection.

A large number of observational studies, dating from as early as 1982 (Larsen et al. 1982), have suggested that short-scale convectively generated gravity waves do indeed play an important role in tropical dynamics. A comprehensive review of these papers is given by Dunkerton (1997). Alexander and Pfister (1995) used aircraft measurements of wind to assess the structure of momentum flux due to convectively generated gravity waves with horizontal length scales between 10 and 100 $\mathrm{km}$. Their results showed that the momentum-flux vectors always pointed away from the regions of strongest updrafts within the cloud.

Recently, Dewan et al. (1998) observed circular patterns in images of the upper stratosphere from satellite data that could very well be interpreted as gravity waves triggered by convection. From their observations the authors estimated a preferred horizontal wavelength between 50 and $25 \mathrm{~km}$ and inferred the period of the oscillations, from measurements of the inclination of the phase lines and the stratification, to be approximately $15 \mathrm{~min}$. These estimates are not too different from those obtained in this study. Also the three-dimensional struc- 
ture of the gravity wave field, that is, circular phase lines on constant height surfaces, resembles that obtained in our simulations (Figs. 3 and 4b).

Two-dimensional simulations of convectively triggered gravity waves have been the object of several studies (Fovell et al. 1992; Alexander et al. 1995; Alexander and Holton 1997). Alexander et al. (1995) examined the link between the structure of the convectively triggered gravity wave field and the wave-forcing mechanism. In their work, they associated the peak in frequency and vertical wavelength of the gravity wave spectrum with the updraft oscillation frequency and the vertical scale of tropospheric latent heating, respective1y. Alexander and Holton (1997) examined the role played by convectively generated gravity waves in the forcing of the quasi-biennial oscillation (hereafter QBO). They used a 900-km-wide and 30-km-deep 2D domain and obtained significant horizontally averaged momentum-flux divergence in the regions of maximum vertical shear with a resulting peak-flow deceleration of $5 \mathrm{~m} \mathrm{~s}^{-1} \mathrm{day}^{-1}$. They suggested that convectively triggered gravity waves could account for up to $1 / 4$ of the required forcing to drive the QBO. Alexander and Holton (1997) point out that this is likely to be an overestimate for various reasons. First, the convective event simulated in their study is representative of a West African squall line, a type of convective event that is more intense than typical tropical storms. Second, their estimate is based on the assumption that all tropical squall lines are aligned in the north-south direction. Third, three-dimensional gravity waves are likely to be less energetic than their two-dimensional counterparts.

Early three-dimensional simulations of convectively generated gravity waves focused on shallow unorganized convection (Hauf and Clark 1989; Kershaw 1995). Recently, Lane et al. (1999, manuscript submitted to $J$. Atmos. Sci.) used a 3D simulation, based on the same type of "Hector" storm considered in the present work, to investigate gravity wave generation by individual updraft cells. One major focus of Lane et al. (1999, manuscript submitted to J. Atmos. Sci.) is on the evolution of individual cells and the manner through which gravity waves are generated by these cells. They also investigated gravity wave momentum fluxes and estimated that convectively generated gravity waves were producing a drag on the mean flow of about $0.029 \mathrm{~m} \mathrm{~s}^{-1}$ day $^{-1}$ over their $320 \mathrm{~km} \times 180 \mathrm{~km}$ domain. This figure is far smaller than that obtained by Alexander and Holton (1997), but the two results are not directly comparable because Lane et al. (1999, manuscript submitted to J. Atmos. Sci.) only simulated cases in which the stratospheric wind speed was constant with height, whereas the results of Alexander and Holton (1997) were obtained for conditions with substantial stratospheric shear.

In this study we use a three-dimensional cloud-resolving mesoscale model to study the morphology of gravity waves generated by organized tropical convection and the interaction of these waves with shear layers representative of the QBO. Following the guidelines given by Alexander et al. (1995), we relate properties of the gravity waves to forcing mechanisms in the storm. We examine the effects of critical layers (defined as the height where the Doppler-shifted frequency is zero) on the morphology of the wave field. We also study the zonal wind forcing due to momentum-flux divergence associated with critical-layer absorption of gravity waves and compute the horizontal averages of the different terms of the zonal momentum equation as a function of height. The analysis of these vertical profiles allows us to roughly estimate the importance of the role played by convectively triggered gravity waves in the dynamics of the tropical lower stratosphere.

An overview of the model and a description of the storm simulation follow in section 2 . In sections 3 and 4 we give the details of the spectral analysis and momentum budget. In section 5 we roughly estimate the total convectively generated gravity wave forcing in the lower stratosphere. Section 6 contains the summary and conclusions.

\section{Numerical model and simulation}

\section{a. Numerical model description}

In this study we use an updated version of the threedimensional mesoscale model similar to that described by Durran and Klemp (1983). Grid nesting is included in the model following the formulation by Skamarock and Klemp (1993). We had intended to perform these calculations using a series of nested grids; however, an unacceptable amount of stratospheric gravity wave reflection occurred at the nested-grid boundaries. Thus, we conducted all the simulations discussed in this paper on a single high-resolution grid. The model equations are

$$
\begin{aligned}
& \frac{d u}{d t}+\theta_{B} \frac{\partial \pi}{\partial x}= D_{u} \quad \frac{d v}{d t}+\theta_{B} \frac{\partial \pi}{\partial y}=D_{v} \\
& \frac{d w}{d t}+\theta_{B} \frac{\partial \pi}{\partial z}= g \frac{\theta_{B}-\bar{\theta}_{B}}{\bar{\theta}_{B}}+D_{w} \\
& \frac{d \pi}{d t}+w \frac{d \Pi}{d z}=-\frac{R}{c_{v}}(\pi+\Pi)\left(\frac{\partial u}{\partial x}+\frac{\partial v}{\partial y}+\frac{\partial w}{\partial z}\right) \\
&+\frac{R}{\bar{\theta}_{B} c_{v}}(\pi+\Pi)\left(\frac{d \theta_{B}}{d t}\right) \\
& \frac{d \theta}{d t}= K_{\theta}+D_{\theta} \quad \frac{d q_{v}}{d t}=K_{q_{v}}+D_{q_{v}} \\
& \frac{d q_{c}}{d t}=K_{q_{c}}+D_{q_{c}} \quad \frac{d q_{r}}{d t}=K_{q_{r}}+D_{q_{r}},
\end{aligned}
$$

where 


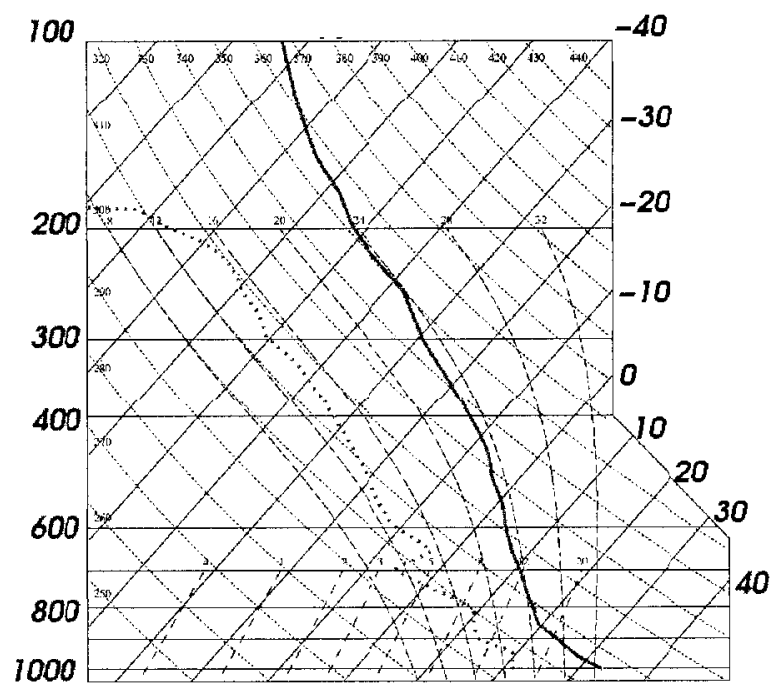

FIG. 1. Sounding obtained from Keenan et al. (1994), representative of the prestorm environment of a convective event triggered on 22 Nov 1988 over Bathurst and Melville Islands.

$$
\begin{aligned}
& \frac{d}{d t}=u \frac{\partial}{\partial x}+v \frac{\partial}{\partial y}+w \frac{\partial}{\partial z} \quad(\pi+\Pi)=c_{p}\left(\frac{p}{p_{0}}\right)^{\left(R / c_{p}\right)} \\
& \theta_{B}=\theta\left(1+0.61 q_{v}\right)\left(1-q_{c}\right) .
\end{aligned}
$$

In the above equations, $p$ is the pressure, $p_{0}=1000$ $\mathrm{mb}, \rho$ is total density, $\theta$ is total potential temperature, and overbars denote the horizontally homogeneous reference states. The $D_{x}$ represents the joint effects of subgrid-scale mixing and computational smoothing on the variable $x$, while $K_{x}$ represents the effect of microphysics; $q_{v}, q_{c}, q_{r}$ are the three water categories of the Kessler parametrization (vapor, cloud water, and rain) described in more detail by Durran and Klemp (1983).

Simulations with both periodic and open lateral boundary conditions were done. The open lateral boundary conditions are similar to those discussed by Fovell et al. (1992). A radiation condition is imposed (Durran 1999, pp. 427-431) at the upper boundary. The size of the computational domain is $500 \mathrm{~km} \times 500 \mathrm{~km}$ in the horizontal and $42 \mathrm{~km}$ in the vertical. The horizontal grid size is $\Delta x=\Delta y=2000 \mathrm{~m}$ everywhere, while the vertical grid size is stretched from $\Delta z=100 \mathrm{~m}$ at the surface to $\Delta z=400 \mathrm{~m}$ at $z=6 \mathrm{~km}$ and above. The purpose of the vertical grid stretching is to better resolve the dynamics of the expanding cold pool and gust front. The integration time step is $\Delta t=4 \mathrm{~s}$.

\section{b. Overview of the storm simulation}

The tropospheric sounding used to initiate convection is based on one obtained from Keenan et al. (1994) and is representative of the prestorm environment of a convective event triggered on 22 November 1988 over Bathurst and Melville Islands just northwest of Darwin, Australia (Fig. 1, also see appendix for tabulated version

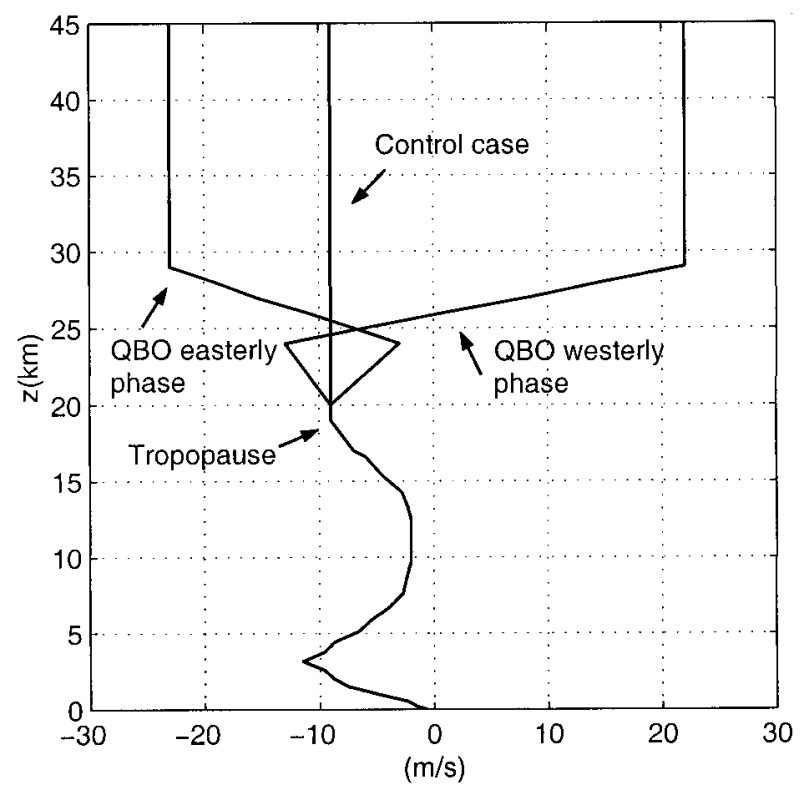

FIG. 2. Background zonal wind profiles used in the simulations. The tropospheric portion is derived from the climatology of the monsoon break period for this region obtained from Keenan and Carbone (1992). The stratospheric portion was obtained from Alexander and Holton (1997) and is representative of the easterly and westerly phases of the QBO.

of sounding). Due to its location $\left(12^{\circ} \mathrm{S}, 131^{\circ} \mathrm{E}\right)$, Darwin's climatology is characterized by intense wet and dry seasons. Most of the annual rainfall occurs during the wet season, which extends from November through April. During this period the low-level winds are usually westerly and of equatorial origin except for so-called transition and break periods when there is a low- to midlevel easterly flow of continental origin (Keenan and Carbone 1992). Large thunderstorms (referred to by the locals as Hectors) occur during the break period. Initially a few small convective cells appear over the larger orographic features. The cells then merge in regions of strong sea breeze convergence (this is referred to as the merger phase), and the system develops rapidly with updrafts reaching $40 \mathrm{~m} \mathrm{~s}^{-1}$ and echo tops up to $20 \mathrm{~km}$. In the mature phase the convective complex aligns itself along the north-south direction, perpendicular to the environmental low-level wind shear, and moves westward with a classic multicellular squall line structure. Although 18-km-high echo tops are still observed, updraft velocities are much weaker during the mature phase (Keenan et al. 1994).

The CAPE associated with our sounding is $2780 \mathrm{~J}$ $\mathrm{kg}^{-1}$; the tropopause is at approximately $19 \mathrm{~km}$. The tropospheric environmental zonal wind profile is derived from the climatology of the monsoon break period (Simpson et al. 1993) (Fig. 2). Thus an $11 \mathrm{~m} \mathrm{~s}^{-1}$ westward jet at about $700 \mathrm{mb}$ is the source of moderate lowlevel vertical wind shear. Above $700 \mathrm{mb}$, the shear reverses until the ground-relative winds reach $-2 \mathrm{~m} \mathrm{~s}^{-1}$ 
at roughly $300 \mathrm{mb}$ where the shear reverses again and the westward wind increases with height up to $-9 \mathrm{~m}$ $\mathrm{s}^{-1}$ at the tropopause. Since the climatological meridional wind profile for the monsoon break period is significantly weaker than its zonal counterpart, the northsouth wind component was set to zero. Finally, the lowest moist layer was thickened, relative to that observed over Darwin, to account for the effect of sea breeze convergence over the islands.

The stratospheric temperature profile was determined by setting the Brunt-Väisälä frequency $\mathrm{N}$ to $0.022 \mathrm{~s}^{-1}$. Three different stratospheric background wind profiles are used; in all cases the meridional component is zero. The wind speed in the first profile, referred to as the control case, is constant with $u=-9 \mathrm{~m} \mathrm{~s}^{-1}$. The other two cases are representative of the easterly and westerly phases of the QBO (Alexander and Holton 1997) (Fig. 2). ${ }^{1}$

The convection was triggered by a north-south line of three warm bubbles, with horizontal and vertical radii of $10 \mathrm{~km}$ and $700 \mathrm{~m}$, respectively, and perturbation temperature of $2 \mathrm{~K}$. The development of organized convection, with a well-defined gust front and cold pool, takes about $3000 \mathrm{~s}(\sim 50 \mathrm{~min})$. At this time the updrafts triggered by the initial bubbles begin to dissipate and new updrafts begin to form. After $10000 \mathrm{~s}(\sim 3 \mathrm{~h})$ the updrafts have gone through 3 to 4 cycles and their number and position appear to be completely uncorrelated with the number and position of the initial warm bubbles. During this period the maximum updrafts are of the order of $20 \mathrm{~m} \mathrm{~s}^{-1}$ (they never exceed $25 \mathrm{~m} \mathrm{~s}^{-1}$ at any time during the simulation) and the storm takes the form of a slightly bowed north-south squall line. These velocities are weaker, by a factor 2 , than those observed during the merger phase of a real Hector event but appear to be representative of the updrafts in the mature phase of an actual Hector storm. The gust front advances westward at $\sim 9 \mathrm{~m} \mathrm{~s}^{-1}$ while increasing its north-south extension at $\sim 3 \mathrm{~m} \mathrm{~s}^{-1}$. The simulation is carried out until $23000 \mathrm{~s}$, at which time the northern and southern edges of the gust front start to be influenced by the domain boundaries. At around $15000 \mathrm{~s}$ the squall line, and the visual pattern of convectively triggered gravity waves in the overlying stratosphere, appear to reach a quasi steady state.

Isosurfaces of vertical velocity, obtained from the control case simulation at 15000 s, are shown in Fig. 3 . The gust front can be recognized as an unbroken wall extending roughly $2 \mathrm{~km}$ up from the ground at the western end of the storm (in the figure, the storm is viewed from the southwest). The top half of the figure shows the concentric cones formed by the isophase surfaces

\footnotetext{
${ }^{1}$ Here, we refer to the easterly phase of the QBO as that phase being characterized by a layer in which winds from the east (conventionally referred to as either easterly winds or westward winds) increase with height.
}

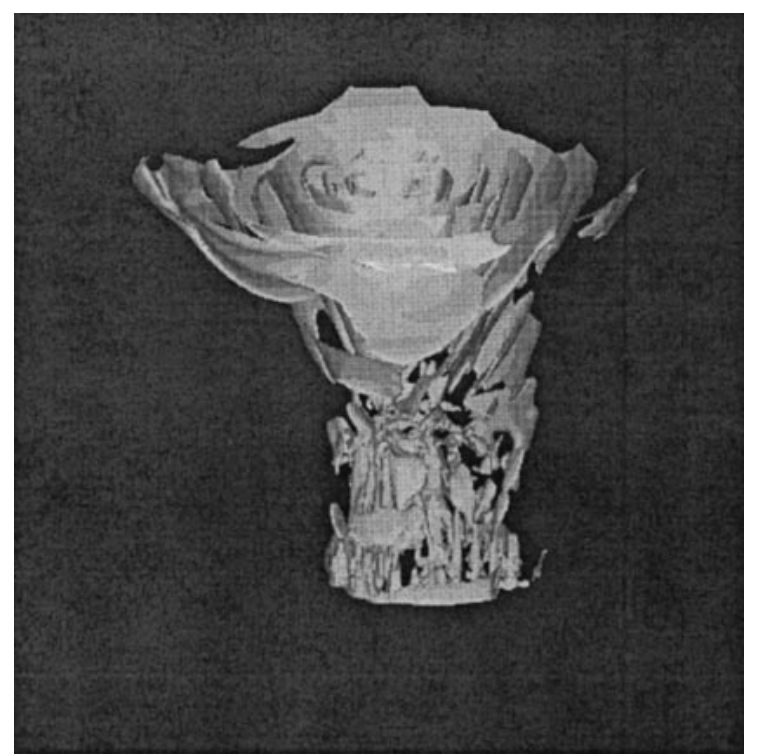

FIG. 3. Isosurfaces of vertical velocity $\left(w=0.2 \mathrm{~m} \mathrm{~s}^{-1}\right)$ obtained from the storm simulation $15000 \mathrm{~s}$. after initialization. The storm is viewed from the southwest. The entire image spans from the surface to $42 \mathrm{~km}$ in height and $500 \mathrm{~km}$ in diameter at the top.

of gravity waves triggered by the storm. A vertical cross section of these isophase surfaces, taken through the center of the domain, is shown in Fig. 4a, and a horizontal cross section taken at $40-\mathrm{km}$ height is shown in Fig. 4b. To facilitate the location of the storm with respect to the gravity wave structure, the outline of the gust front and regions of strong latent heating are also shown in Fig. 4b. These cross sections reveal an almost circularly symmetric structure at all levels. The waves appear to emanate from a point source within the region of maximum latent heating. The primary cause of deviation from circular symmetry is the greater amplitude in the eastward traveling waves. This enhancement in the amplitude of those waves propagating rearward with respect to the gust front, which is also visible in Fig. 4a, appears to be produced by the systematic rearward propagation of individual convective elements and is consistent with the results from previous 2D simulations by Fovell et al. (1992) and Alexander et al. (1995).

Critical-level absorption has a dramatic influence on the wave field in those cases with stratospheric winds representative of the two phases of the QBO. In the westerly phase-QBO simulation, the eastward propagating waves are dissipated as they approach their critical levels in the layer of strong eastward shear between $z=24$ and $29 \mathrm{~km}$, as shown in Fig. 5a. As a consequence, the eastern half of the cone of vertically propagating gravity waves found in the control case is eliminated in the westerly phase-QBO simulation (compare Figs. 3 and 6). The opposite result is obtained in the easterly phase-QBO simulation shown in Figs. 7 and 8 . In this case it is the westward propagating waves that 
are removed by critical-layer absorption, and the western half of the cone of vertically propagating gravity waves is almost eliminated. Another effect of the shear layers is the refraction of the waves that are not damped. In Fig. 5a the westward traveling waves are refracted toward the vertical while crossing the shear layer. In Fig. 8a it is the eastward traveling waves that are refracted toward the vertical while crossing the shear layer. The refraction of the waves toward the vertical (decrease in the vertical wavenumber $m$ ) is consistent with the dispersion relation [Eq. (4)]. This effect is not as important for the dynamics of the QBO as critical-layer absorption since there is little or no momentum deposition occurring (Elliassen and Palm 1960).

\section{Spectral analysis}

Due to limitations on our computational resources, only a subset of the total space-time domain was employed in the following spectral analysis. Thirteen zonal-vertical cross sections of a given variable $\alpha$, extending through the entire domain in the zonal direction $\left(L_{x}\right.$ $=500 \mathrm{~km}$ ) and from $z=18 \mathrm{~km}$ to the top boundary in the vertical (the entire depth of the simulated stratosphere), were archived every $100 \mathrm{~s}$ from $t_{0}=15000 \mathrm{~s}$ to $t_{1}=23000 \mathrm{~s}$. These 13 cross sections were spaced $8 \mathrm{~km}$ apart along the meridional coordinate, the first one being at $y=200 \mathrm{~km}$ and the last at $y=296 \mathrm{~km}$. Together, the cross sections form a meridional band, 100 $\mathrm{km}$ wide, passing through the center of the domain. The resulting dataset constitutes a 4D array in longitude, latitude, height, and time $\alpha\left(x_{i}, y_{j}, z_{k}, t_{n}\right)$. This dataset was used to obtain a $2 \mathrm{D}$ power spectrum in zonal wavenumber and frequency $\hat{\hat{\alpha}}\left(\kappa_{i}, \omega_{n}\right)$.

The Fourier transform algorithm used to obtain the 2D power spectrum is similar to that described by Alexander et al. (1995). First we take the discrete Fourier transform of the variable $\alpha$ with respect to $x$ to obtain $\mathcal{F}_{x}(\alpha)\left(\kappa_{i}, y_{j}, z_{k}, t_{n}\right)$. Then we take the discrete Fourier transform of $\mathcal{F}_{x}(\alpha)$ with respect to $t$ to obtain $\mathcal{F}_{t}\left[\mathcal{F}_{x}(\alpha)\right]\left(\kappa_{i}, y_{j}, z_{k}, \omega_{n}\right)$. A height- and latitude-dependent power spectrum is calculated as

$$
\begin{aligned}
\hat{\alpha}\left(\kappa_{i}, y_{j}, z_{k}, \omega_{n}\right)= & \mathcal{F}_{t}\left[\mathcal{F}_{x}(\alpha)\right]\left(\kappa_{i}, y_{j}, z_{k}, \omega_{n}\right) \\
& \times \text { conjugate }\left\{\mathcal{F}_{t}\left[\mathcal{F}_{x}(\alpha)\right]\left(\kappa_{i}, y_{j}, z_{k}, \omega_{n}\right)\right\} .
\end{aligned}
$$

The resulting spectrum contains both positive and negative frequencies and wavenumbers. Since the initial dataset is real, the information contained in the spectrum is redundant in the sense that the $(\omega>0, \kappa>0)$ and $(\omega>0, \kappa<0)$ quadrants are the specular image of the $(\omega<0, \kappa<0)$ and $(\omega<0, \kappa>0)$ quadrants, respectively. In order to eliminate this redundancy, only the $\kappa>0$ part of the spectrum is retained, in which case positive (negative) frequencies represent eastward (westward) traveling waves. A meridionally and vertically averaged density-weighted $2 \mathrm{D}$ spectrum $\overline{\hat{\alpha}}$ is then computed as
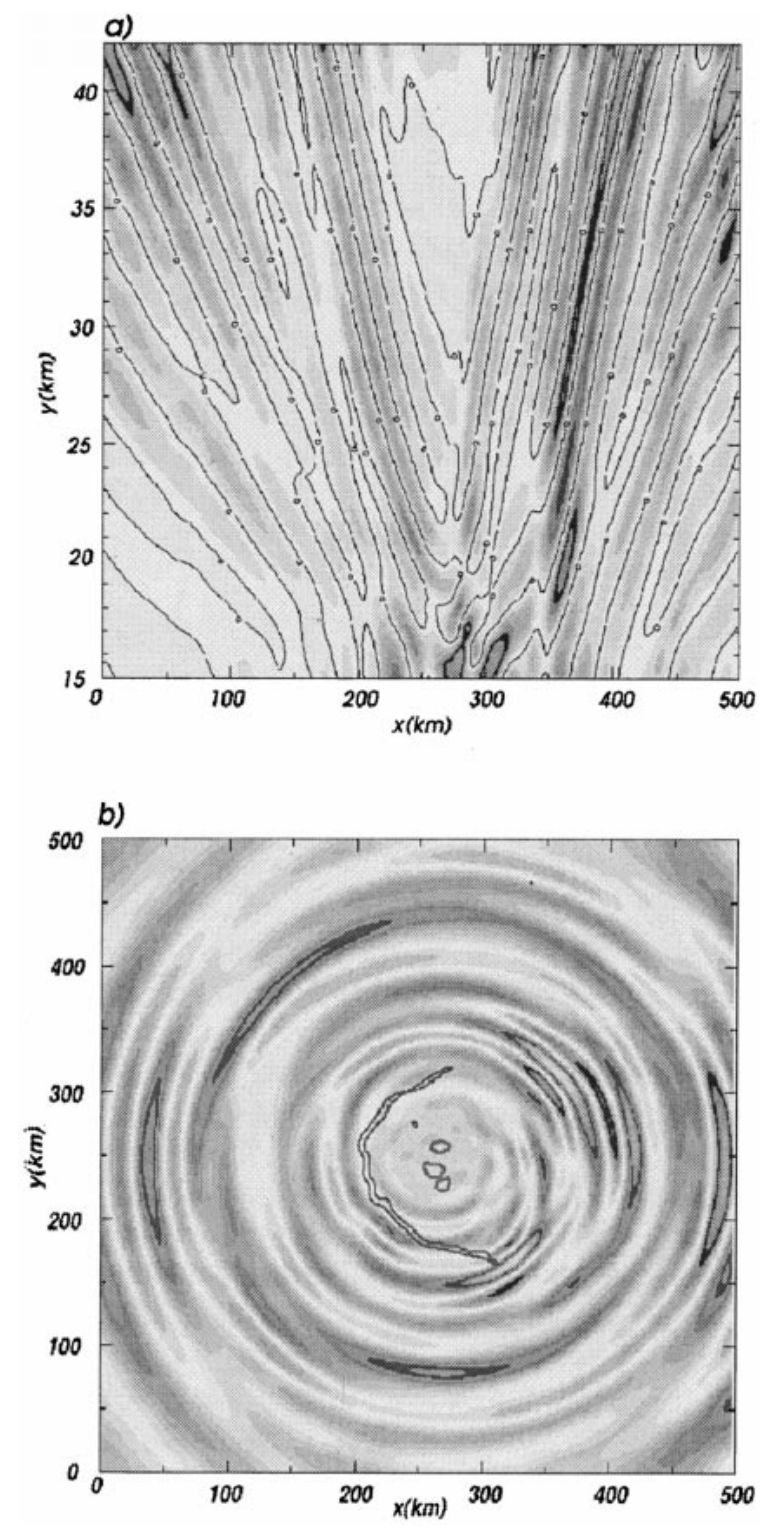

FIG. 4. (a) Vertical-zonal cross section of vertical velocity (shaded field) at $t=15000 \mathrm{~s}$ and $y=250 \mathrm{~km}$. The solid line is the 0 contour. The shading interval is $0.1 \mathrm{~m} \mathrm{~s}^{-1}$. (b) Horizontal cross section of the entire domain at $t=15000 \mathrm{~s}$ and $z=40 \mathrm{~km}$. The shaded field is vertical velocity. The thick line is the $0.2 \mathrm{~m} \mathrm{~s}^{-1}$ contour of vertical velocity at $z=200 \mathrm{~m}$. The thickest contours in the center of the figure enclose regions of strong latent heating at $z=8 \mathrm{~km}$.

$\overline{\hat{\alpha}}\left(\kappa_{i}, \omega_{n}\right)=\frac{1}{J K \rho\left(z_{1}\right)} \sum_{j=1}^{J} \sum_{k=1}^{K} \hat{\alpha}\left(\kappa_{i}, y_{j}, z_{k}, \omega_{n}\right) \rho\left(z_{k}\right)$.

This spectrum is normalized so that

$$
\sum_{i=1}^{(I / 2)+1} \sum_{n=-(N / 2)}^{N / 2} \overline{\hat{\alpha}}\left(\kappa_{i}, \omega_{n}\right)=\sum_{i=1}^{I} \sum_{n=1}^{N} \overline{\alpha^{2}}\left(x_{i}, t_{n}\right) .
$$

Here, $\kappa_{(I / 2)+1}$ and $\omega_{N / 2}$ are the highest resolved zonal wavenumber and frequencies, respectively; $x_{1}=0 ; x_{I}$ 


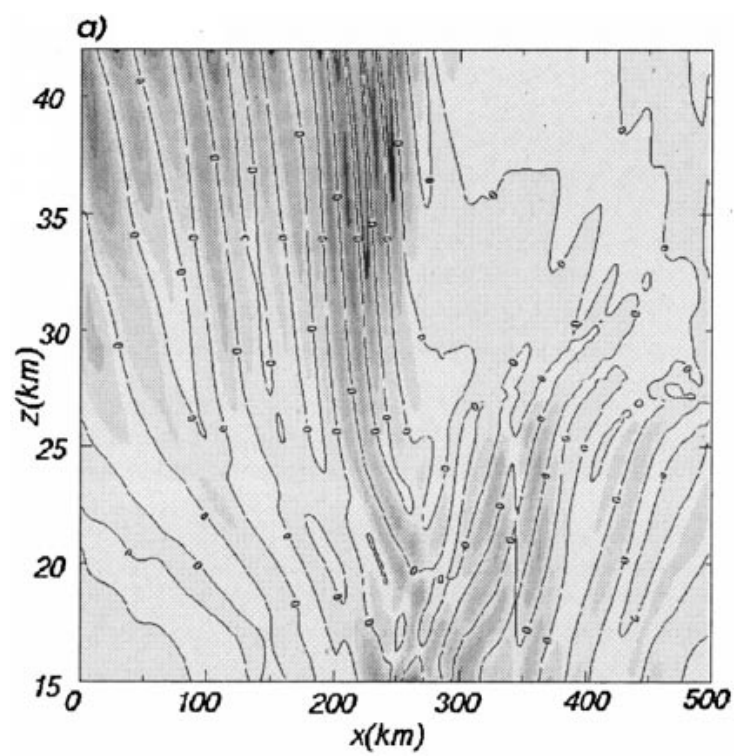

b)

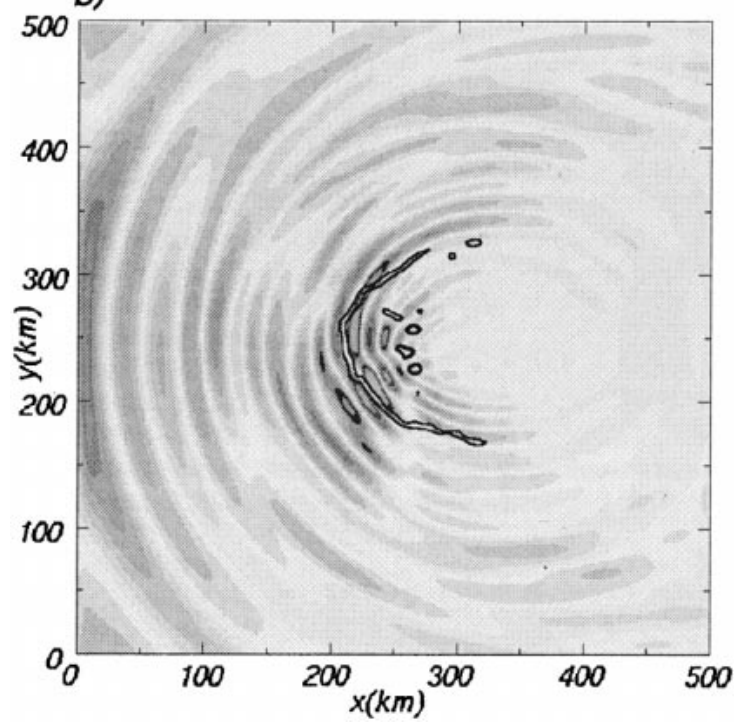

FIG. 5. Like Fig. 4 but for the case of westerly phase of the QBO.

$=L_{x}$; and $\left(t_{1}, t_{N}\right)$ is the time interval used for spectral analysis. The overbar indicates the quantity has been averaged in the $y-z$ domain using density as a weighting function.

Contours for $\log _{10}(\overline{\hat{\alpha}})$ for the control case are shown in Fig. 9. The 2D spectrum for this case shows two peaks: one associated with eastward traveling waves (positive frequency) and one associated with westward traveling waves (negative frequency). These peaks roughly correspond to a period and a wavelength of 35 min and $40 \mathrm{~km}$, respectively. Because the $\log _{10}$ of the spectrum is contoured in Fig. 9, the peaks appear less pronounced than if the spectrum itself was contoured, but one can more easily appreciate its less energetic

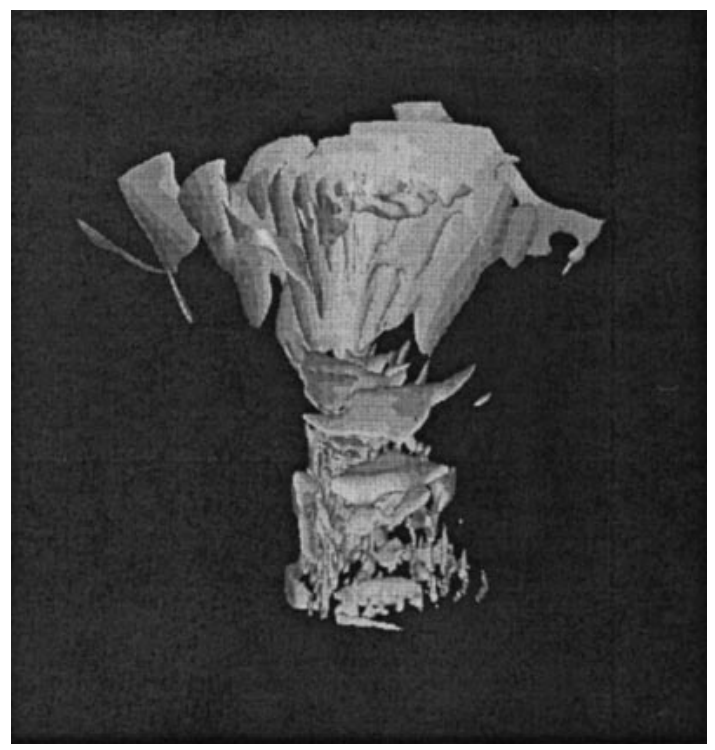

FIG. 6. Same as Fig. 3 but for the westerly phase of the QBO. To better distinguish the effect of the shear layers, the storm is here viewed from the southeast.

features. As mentioned earlier, the data used for spectral analysis were taken from vertical east-west cross sections. Since these pass close to the center of the storm, the phase lines of the waves traversed by the cross sections are oriented in the north-south direction (Fig. 4b). These waves may, therefore, be approximated as planeparallel with $y$ wavenumber equal to zero, in which case, the $2 \mathrm{D}$ gravity wave dispersion relation can be solved for the vertical wavenumber to obtain

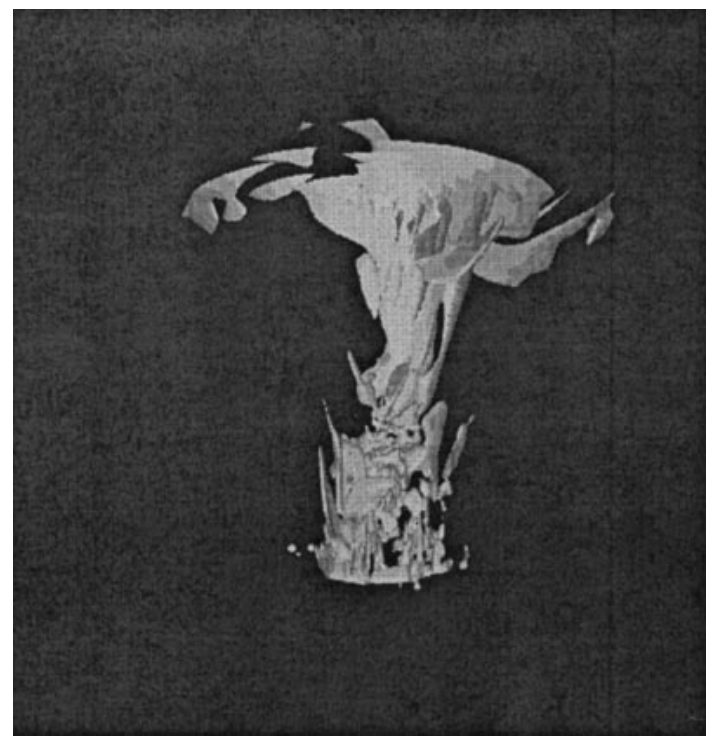

FIG. 7. Same as Fig. 3 but for the easterly phase of the QBO. The storm is here viewed from the southwest. 

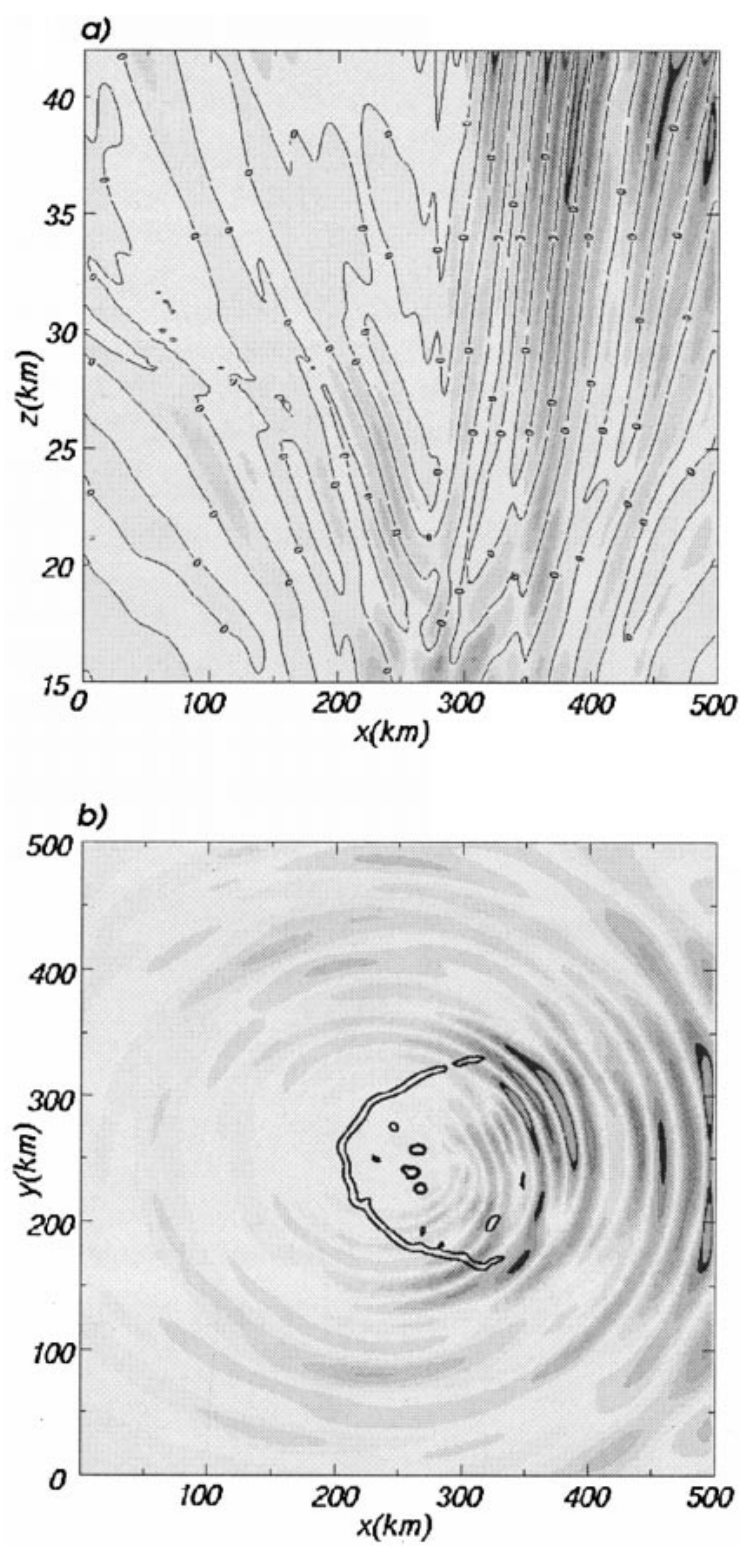

FIG. 8. Like Fig. 4 but for the case of easterly phase of the QBO

$$
m=\sqrt{\frac{N^{2} \kappa^{2}}{(\omega-U \kappa)^{2}}-\kappa^{2}},
$$

where $U$ is the storm-relative zonal wind ( $U=0$ in the control case). This relation was used to plot the lines of constant vertical wavelength superimposed on Fig. 9. Comparing the lines of constant vertical wavelength with the orientation of the spectral peaks in Fig. 9, we conclude that the most energetic disturbances have a preferred vertical wavelength of 4-7 km.

It has been often suggested that the preferred vertical wavelength of the convectively triggered gravity wave field is directly related to the vertical profile of latent heating in the strong central updrafts (Salby and Garcia 1987; Pandya et al. 1993; Alexander et al. 1995). Our

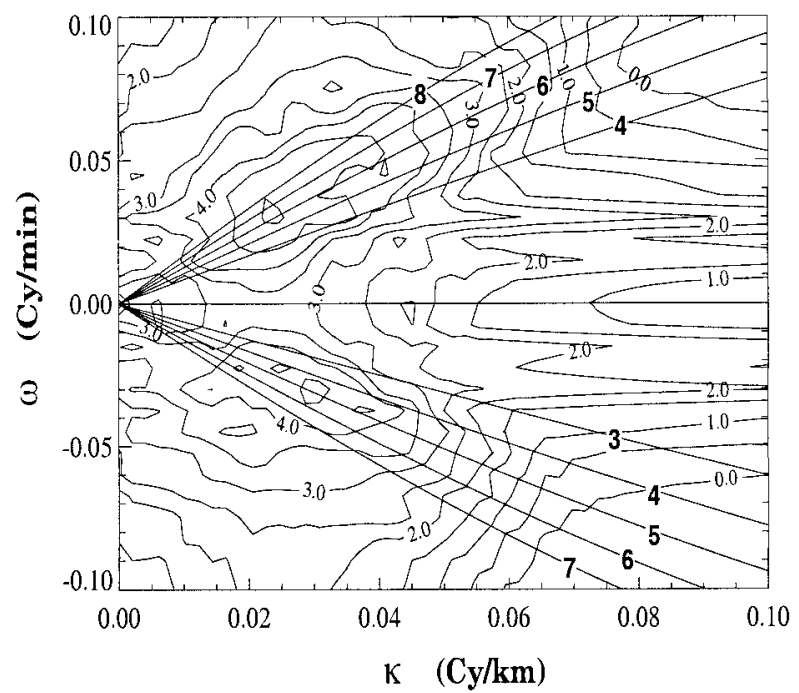

FIG. 9. Base 10 logarithm of 2D average spectrum in frequency $(\omega)$ and horizontal wavenumber $(\kappa)$ of vertical velocity. Positive (negative) frequencies represent eastward (westward) traveling waves. The superimposed lines are contours of vertical wavelength (labeled in $\mathrm{km}$ ).

results support this theory. According to Salby and Garcia (1987), the wave response to a transient localized heating in a stable atmosphere will have a preferred vertical wavelength that depends only on the vertical scale of the heating profile and not on its details. The vertical profile of latent heating within the storm is shown in Fig. 10 (solid line). This profile was fitted with a sinusoidal wave of the form $\sin (m z+\gamma)$ (dashed lined), where $m$ is the vertical wavenumber and $\gamma$ is the

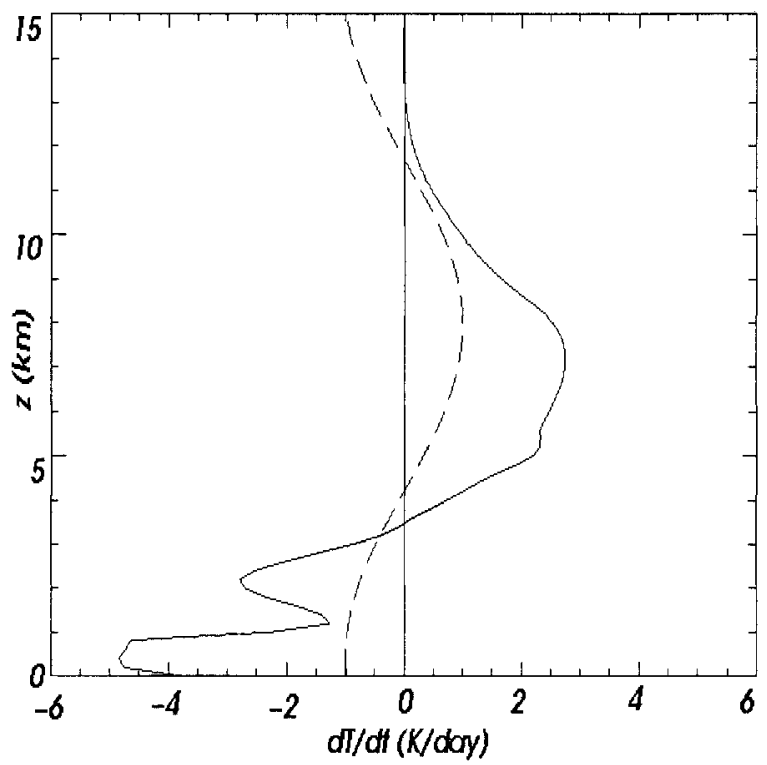

FIG. 10. Vertical profile of latent heating averaged over the entire domain of the simulation from $10000 \mathrm{~s}$ to $15000 \mathrm{~s}$ after initialization. The superimposed sine wave (dashed line) is the one onto which the projection of the heating profile is maximum. 


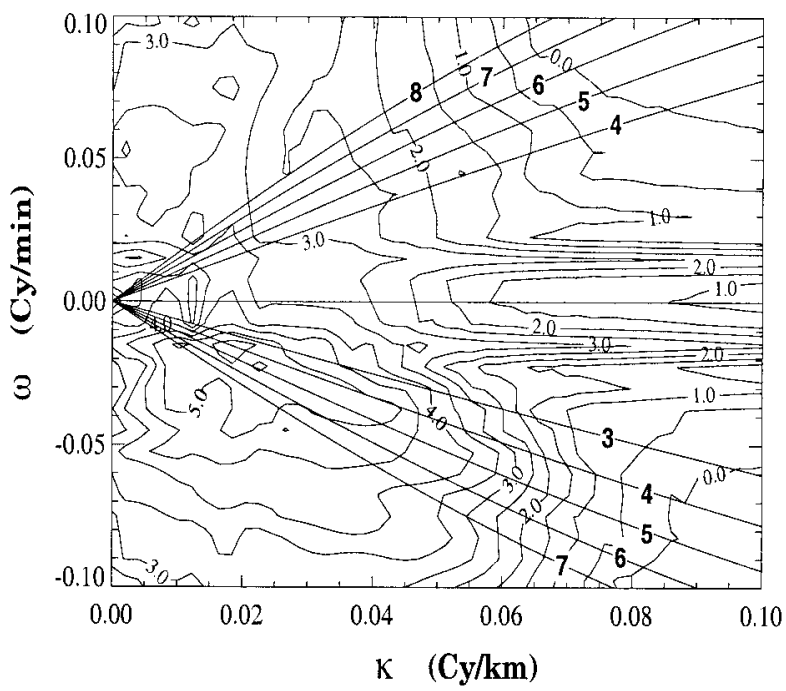

FIG. 11. Like Fig. 9 but for the westerly phase of the QBO.

phase offset. The chosen values of $m$ and $\gamma$ are those that maximize the projection of the heating profile onto the sinusoidal wave. The vertical wavelength of the resulting sine wave is $15 \mathrm{~km}$.

According to the dispersion relation [Eq. (4)], refraction across the tropopause, due to a doubling of the buoyancy frequency, will cause a decrease by a factor 2 in the vertical wavelength of nearly hydrostatic upward traveling waves. Hence, the expected dominant vertical wavelength in the stratosphere produced by the heating profile in Fig. 10 is $7.5 \mathrm{~km}$, approximately matching the results obtained from our spectral analysis.

Two-dimensional spectral analyses are also shown for the westerly-shear case in Fig. 11 and for the easterlyshear case in Fig. 12. For these cases, only that part of the wave field lying above the shear layer, namely, the region from $z=30 \mathrm{~km}$ to $z=42 \mathrm{~km}$, was used in the analysis. This subdomain was chosen to focus only on those waves that had already traversed the shear layer. The contours of vertical wavelength are the same as those shown in Fig. 9. Since $U \neq 0$ above the shear layers in the QBO simulations, these contours are not representative of the vertical wavelength at these levels. Instead they are representative of the vertical wavelength of the waves before they are refracted across the shear layer. This was done to make the comparison between simulations and comparison with the vertical scale of latent heating easier. Clearly, the main difference from the control case spectra is the absence of westward (eastward) traveling waves in the presence of westward (eastward) shear.

\section{Momentum fluxes}

Eastward (westward) upward propagating gravity waves dissipate as they approach their critical levels

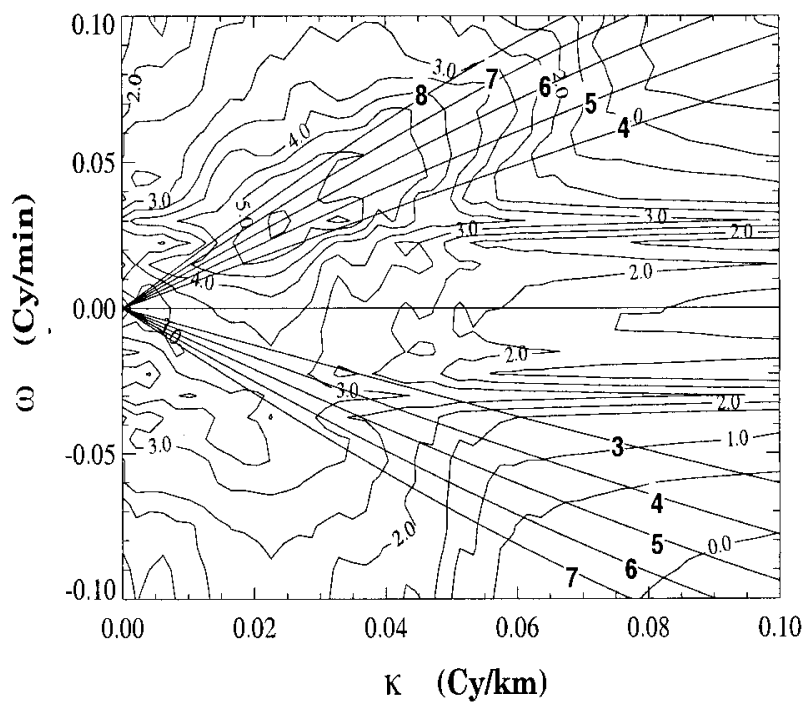

FIG. 12. Like Fig. 9 but for the easterly phase of the QBO.

where the vertical momentum-flux divergence exerts an eastward (westward) force on the mean flow. The precise process through which gravity waves are dissipated as they approach their critical level is not simulated in detail in this study. In our model, gravity waves undergo critical-level absorption when their vertical wavelength decreases, due to refraction across the shear layer, until they reach the resolution limit imposed by vertical-grid spacing. It is often supposed that the mean zonal winds will be accelerated or decelerated at these levels according to the relation

$$
\frac{\partial}{\partial t} \overline{\rho u}=-\frac{\partial}{\partial z} \overline{\rho u^{\prime} w^{\prime}},
$$

where the overbars represent horizontally averaged quantities. A complete analysis of the zonal-momentum budget, however, reveals a more complex mean-flow response in simulations with open-boundary conditions.

Consider the zonal-momentum equation

$$
\begin{gathered}
\frac{\partial \rho U}{\partial t}+\frac{\partial \rho U^{2}}{\partial x}+\frac{\partial \rho U V}{\partial y}+\frac{\partial \rho U W}{\partial z} \\
=-f \rho V-\frac{\partial P}{\partial x}+\rho M,
\end{gathered}
$$

where $U, V$, and $W$ are the total zonal, meridional, and vertical velocities, respectively; $\rho$ is total density; $P$ is total pressure; and $M$ is the forcing due to subgrid-scale mixing and smoothing. If we separate the dynamic variables into their horizontal mean and perturbation components $\left(U=\bar{u}+u^{\prime} ; V=\bar{v}+v^{\prime} ; W=\bar{w}+w^{\prime} ; P\right.$ $=\bar{p}+p^{\prime}$ ) and take the horizontal average of (6) for the case of a nonrotating atmosphere $(f=0)$, we obtain the following equality: 


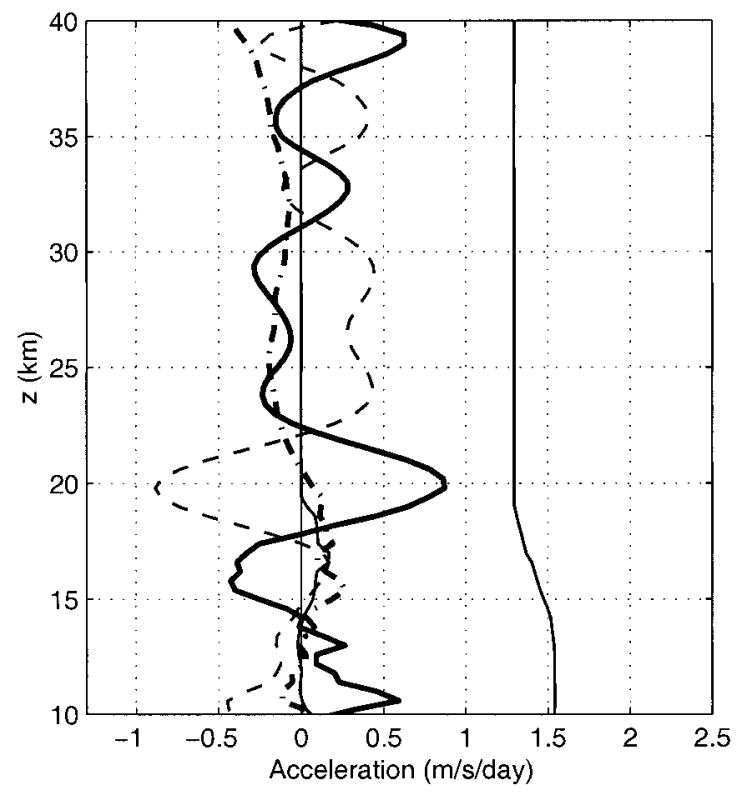

FIG. 13. Vertical profiles of the horizontally averaged zonal momentum-balance terms, divided by $\bar{\rho}$, for the control case. The profiles were time-averaged over the last $8000 \mathrm{~s}$ of the simulation. The thin solid line, offset to the right, is the wind profile (no units). The solid thick line is mean zonal momentum acceleration [first term on the lhs of Eq. (7)]. The thin dashed line is the cross-domain difference in the dynamic pressure [second term on the lhs of Eq. (7)]. The thick dot-dashed line is vertical momentum-flux divergence. Finally, the thin solid line, fairly difficult to see in this figure but more evident in Fig. 14, is the vertical momentum advection [fourth term on the lhs of Eq. (7)].

$$
\begin{aligned}
\frac{\partial}{\partial t} \overline{\rho U} & +\frac{1}{L_{x} L_{y}} \int_{0}^{L_{y}}\left[\rho u^{\prime}\left(u^{\prime}+\bar{u}\right)+p^{\prime}\right]_{0}^{L_{x}} d y \\
+ & \frac{1}{L_{x} L_{y}} \int_{0}^{L_{x}}\left[\rho u^{\prime}\left(v^{\prime}+\bar{v}\right)\right]_{0}^{L_{y}} d x+\overline{W \rho} \frac{\partial \bar{u}}{\partial z} \\
& +\overline{\bar{u}\left(\frac{\partial \rho U}{\partial x}+\frac{\partial \rho V}{\partial y}+\frac{\partial \rho W}{\partial z}\right)}+\frac{\partial}{\partial z} \overline{\rho u^{\prime} w^{\prime}}=0,
\end{aligned}
$$

where the overbars represent horizontally averaged quantities; $[\alpha]_{\beta}^{\gamma}$ is $\alpha(\gamma)-\alpha(\beta)$; and $L_{x}$ and $L_{y}$ are the east-west and north-south extents of the domain, respectively. The horizontal average of the mixing and smoothing term ' $\overline{\rho M}$ ' is zero since subgrid-scale mixing does not occur in the stratosphere and only horizontal smoothing is done on $U$.

The first term on the lhs is the horizontally averaged zonal-momentum acceleration. The second term is the meridional average of the differential advection of zonal momentum plus the pressure difference between the east and west boundaries; this term can also be referred to as a horizontal average of the dynamic-pressure gradient. The third term is the zonal average of the differential meridional advection of zonal momentum between the north and south boundaries. The fourth term
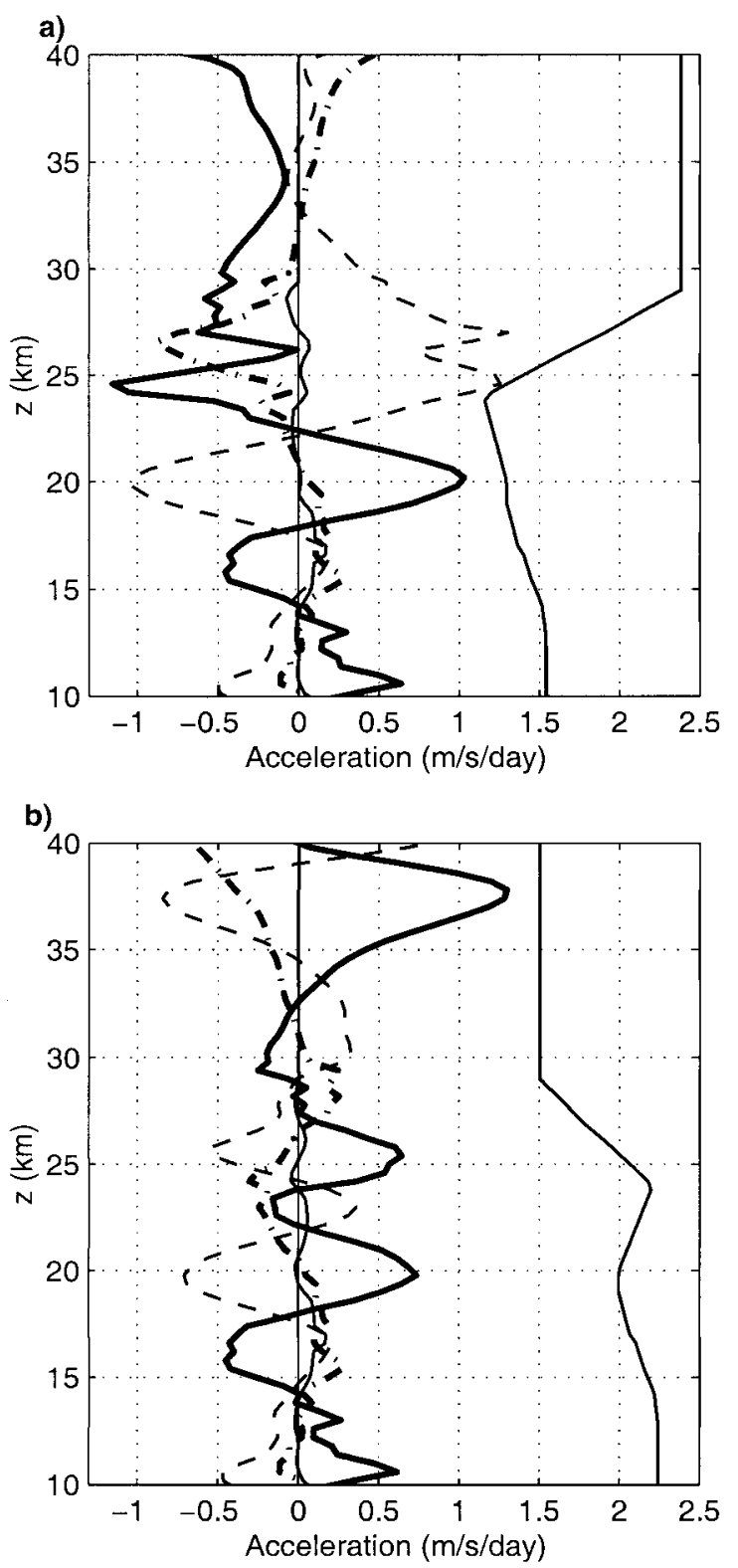

FIG. 14. Like Fig. 13 but for the westerly (a) and easterly (b) phases of the QBO.

is the vertical advection of momentum by the mean vertical velocity. The fifth term on the lhs is proportional to the horizontally averaged density fluctuations $(\bar{u} \overline{\partial \rho / \partial t})$. The third and fifth terms on the lhs of (7) turned out to be, after evaluation, an order of magnitude smaller than the rest. Finally, the last term on the lhs is the horizontally averaged divergence of the vertical flux of zonal momentum.

Vertical profiles of the largest four terms in (7), divided by $\bar{p}$, are shown for the control case in Fig. 13 and for the two phases of the QBO in Fig. 14. These profiles were time-averaged over the last $8000 \mathrm{~s}$ of the simulation. 
It may appear surprising that there is any vertical momentum-flux divergence in the control case shown in Fig. 13, since without vertical shear in the mean stratospheric-wind profile there is no critical-level absorption of upward propagating gravity waves. (Note that the wave amplitudes are too small to produce dissipation via wave breaking in the lower stratosphere as a result of the decrease in mean density with height.) Similar results, in which numerically simulated, convectively generated stratospheric gravity waves were associated with a nonzero vertical momentum-flux divergence, were obtained by Lane et al. (2000). They argued that the nonzero vertical divergence of $\left(\overline{\rho w^{\prime} u^{\prime}}\right)$ was due to the transient nature of the wave source.

In our simulations it appears that the vertical momentum-flux divergence is primarily produced by waves escaping through the lateral boundaries of the domain. As will be discussed (in connection with Fig. 16), the eastward propagating waves in the control case transport more momentum flux than the westward propagating waves. Thus, as the disturbance escapes through the lateral boundaries, there will be a decrease in eastward momentum flux with height leading to the negative values of $\partial \overline{\rho u^{\prime} w^{\prime}} / \partial z$ apparent throughout the stratosphere in Fig. 13. Further evidence in support of this mechanism is provided by the sign of the momentum-flux divergence in the 30-40-km layer of the westerly and easterly phase-QBO simulations shown in Fig. 14. There is no shear in this layer in either simulation, but the westerly (easterly) shear at lower levels in the stratosphere filters out most of the eastward (westward) propagating gravity waves in the westerly phase (easterly phase) simulation. As a consequence, those waves transporting momentum through the lateral boundaries in the $30-40-\mathrm{km}$ layer create a net decrease in eastward (westward) momentum flux with height and a negative (positive) vertical momentum-flux divergence in the 30-40km layer in Fig. 14a (Fig. 14b).

The most striking aspect of the profiles shown in Figs. 13 and 14 is that the acceleration of the mean flow is primarily balanced by the difference in the dynamic pressure $\left[\rho u^{\prime}\left(u^{\prime}+\bar{u}\right)+p^{\prime}\right]$ across the domain. In the control case, in which there is no shear in the stratospheric mean flow, the vertical momentum-flux divergence is relatively small. Larger absolute values of momentum-flux divergence are found in the westerly and easterly phase-QBO simulations in association with the regions of stratospheric wind shear. As in the control case, the fluid response to the momentum flux divergence in the QBO-shear simulations takes the form of a large dynamic pressure difference between the east and west boundaries that is primarily balanced by an acceleration of the mean flow.

These results are similar to those obtained by Durran (1995), who evaluated momentum budgets in breaking mountain waves; the mean-flow response to a region of gravity wave-induced momentum-flux divergence can be spread rapidly over a very large domain. In particular, Durran found that breaking gravity waves failed to produce a significant net mean-flow deceleration in a 500$\mathrm{km}$-wide region surrounding a $40-\mathrm{km}$-wide mountain, and that the difference across the domain in the dynamic pressure played a major role in the domain-averaged momentum budget. Nevertheless, the atmosphere is horizontally periodic, and the vertical divergence of the zonal momentum fluxes observed in these simulations would, therefore, be expected to produce a change in the zonal momentum averaged around an entire latitude circle. To clearly capture such wave-induced flow acceleration within the computational domain, the preceding simulations were repeated using periodic lateral boundary conditions. Figures will be presented for the particularly simple case of doubly periodic lateral boundaries, but the assumption of periodicity in the meridional direction had only a minor influence on these results. The periodic domain simulations may be alternatively interpreted as representing a situation in which the entire equatorial region is filled with regularly spaced tropical squall lines at a density of one storm per $250000 \mathrm{~km}^{2}$.

Vertical profiles of the largest four terms in (7), divided by $\bar{p}$, are shown in Fig. 15 for periodic-domain simulations of both the westerly and easterly phases of the QBO. In contrast to the open-domain simulations shown in Fig. 14, the mean-flow acceleration in the periodic-domain simulations is almost exactly balanced by the vertical momentum-flux divergence. Although the horizontally averaged dynamic-pressure gradient is null in periodic-boundary simulations, the term was calculated explicitly because its deviations from zero are a good measure of the error in the profiles. Note that the vertical momentum-flux divergence above $30 \mathrm{~km}$, where no shear is present, is almost null by comparison to the open-boundary runs. Since no waves are leaving the domain in the periodic-boundary simulation, this supports the idea that most of the averaged vertical momentum-flux divergence above $30 \mathrm{~km}$ in the openboundary simulations is due to waves exiting the domain. As might be expected, there is no significant vertical momentum-flux divergence, and no significant mean acceleration of the stratospheric flow, when the control case is simulated with periodic-boundary conditions (not shown).

Below $30 \mathrm{~km}$, the profiles of vertical momentum-flux divergence, for a particular QBO-phase case, are surprisingly similar regardless the type of lateral boundary condition (compare Fig. 14a with 15a and Fig. 14b with 15b). Apparently almost all the critical-layer damping occurs within the $500 \mathrm{~km} \times 500 \mathrm{~km}$ simulation domain. In the westerly QBO-phase case (Fig. 15a), the region of strong momentum-flux divergence extends across the layer from 24 to $30 \mathrm{~km}$ and $(1 / \bar{p})\left(\partial \overline{\rho u^{\prime} w^{\prime}} / \partial z\right)$ peaks at about $-1 \mathrm{~m} \mathrm{~s}^{-1}$ day $^{-1}$ with an average of about -0.6 $\mathrm{m} \mathrm{s}^{-1}$ day $^{-1}$ over a 3-km layer centered about the peak. In the easterly $\mathrm{QBO}-$ phase case there are two regions 

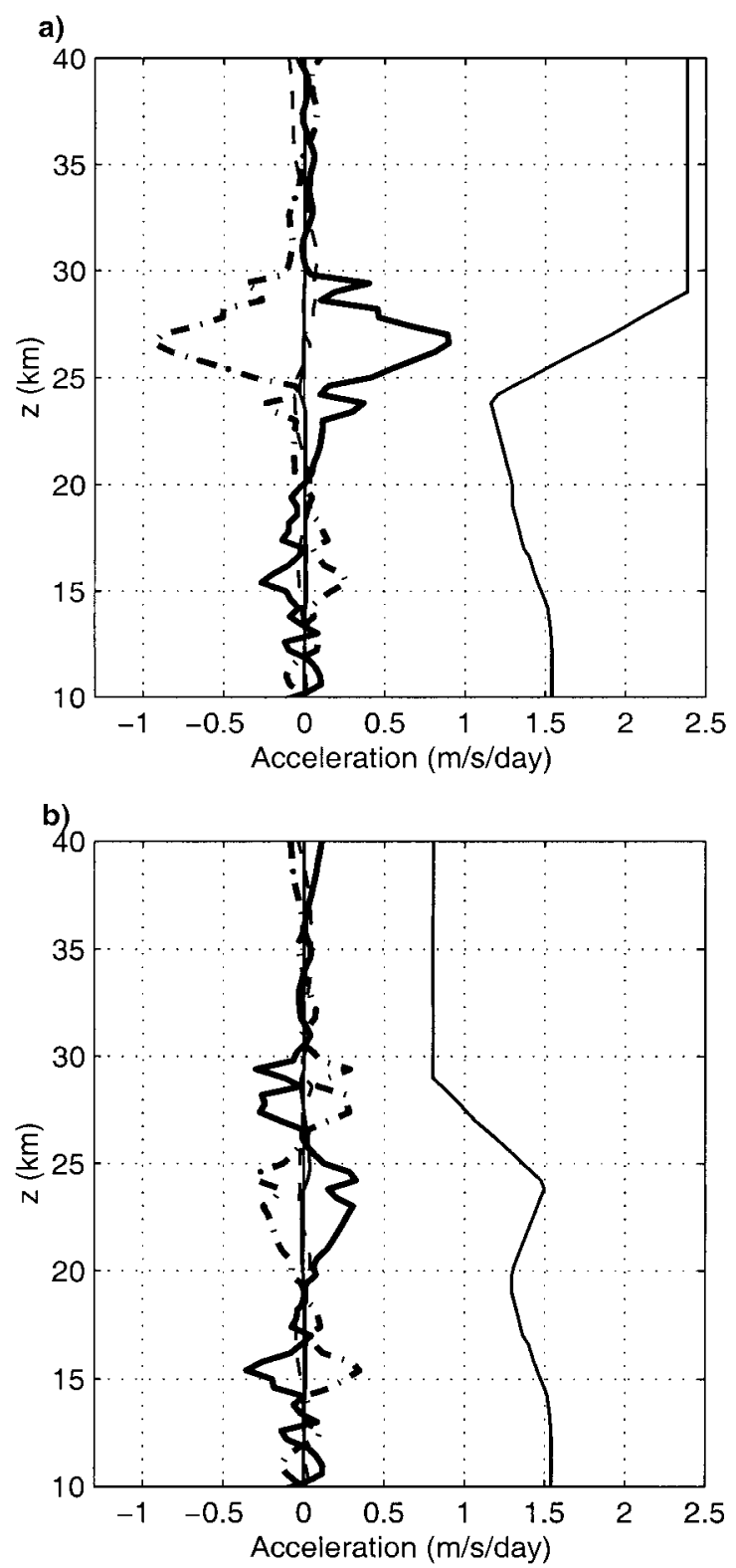

FIG. 15. Like Fig. 13 but for the periodic-boundary simulation of the westerly (a) and easterly (b) phases of the QBO.

of strong vertical momentum-flux divergence in the stratosphere. These regions extend from 20 to $25 \mathrm{~km}$ and from 26 to $30 \mathrm{~km}$. In the lower region $(1 / \bar{p})\left(\partial \overline{\rho u^{\prime} w^{\prime}} / \partial z\right)$ peaks at about $-0.3 \mathrm{~m} \mathrm{~s}^{-1} \mathrm{day}^{-1}$. In the upper region, which loosely corresponds to the easterly-shear layer, $(1 / \bar{p})\left(\partial \overline{\rho u^{\prime} w^{\prime}} / \partial z\right)$ peaks at about $0.3 \mathrm{~m}$ $\mathrm{s}^{-1}$ day $^{-1}$ with an average of about $0.2 \mathrm{~m} \mathrm{~s}^{-1}$ day $^{-1}$ over a 3-km layer centered about the peak. In both the easterly and westerly phases of the QBO, the gravity waveinduced acceleration of the mean flow results in a downward propagation of the shear layers. In the westerlyphase case, however, the vertical momentum-flux di-

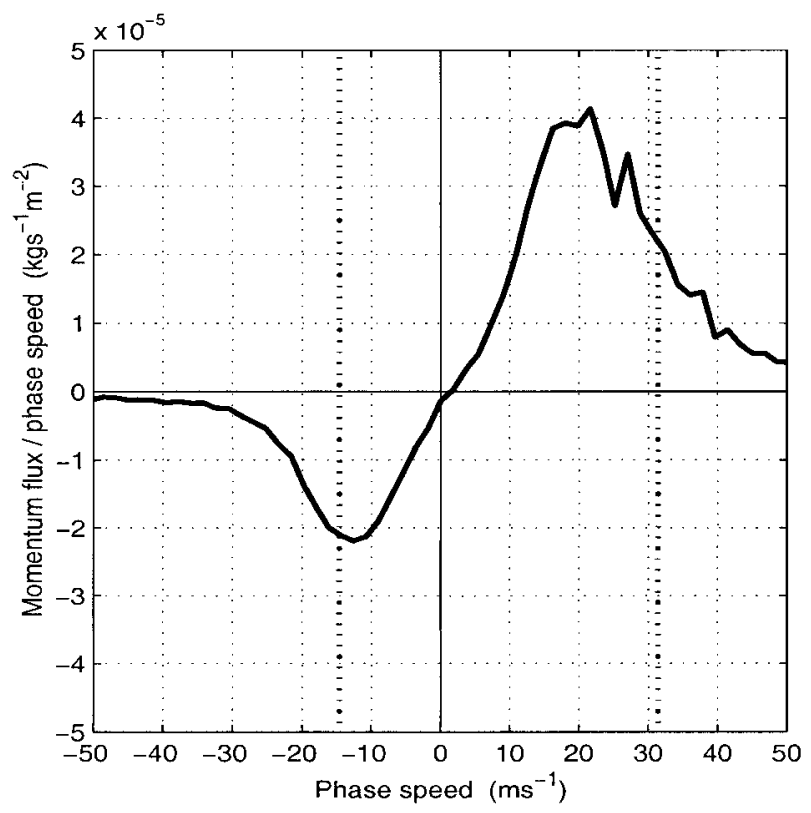

FIG. 16. Momentum flux as a function of phase speed. The two vertical dotted lines correspond to the maximum storm relative wind speeds, encountered above $z=30 \mathrm{~km}$, for the easterly phase-QBO simulation (at $-14 \mathrm{~m} \mathrm{~s}^{-1}$ ) and westerly phase-QBO simulation (at $\left.31 \mathrm{~m} \mathrm{~s}^{-1}\right)$.

vergence is significantly stronger (in absolute value). This difference in the momentum-flux divergence between the two phases of the QBO might be due to either (i) differences in the amplitudes of the eastward and westward propagating waves generated by the convection, or (ii) the difference in the magnitude of the lower stratospheric-wind shear between the westerly and easterly phases of the QBO.

To determine which of these two factors is the primary cause for the magnitude differences between the vertical momentum-flux divergence in the two QBO cases, we plotted the momentum flux transported by the waves as a function of the phase speed of the waves in Fig. 16. This figure was obtained from the bidimensional cospectrum of $u^{\prime}$ and $w^{\prime}$ for the control case by dividing the phase speed axis into bins with $\Delta c_{x}=1 \mathrm{~m} \mathrm{~s}^{-1}$. To each bin $c_{x o}$, corresponds the 2D integral in $d \omega d \kappa$ of the cospectra over the area where $c_{x o}-0.5<\omega \kappa^{-1}<$ $c_{x o}+0.5$. Finally, the momentum fluxes are normalized so that their integral in $d c_{x}$ is equal to the average of $\overline{\rho u^{\prime} w^{\prime}}$ over the entire stratosphere and over the last 8000 $\mathrm{s}$ of the simulation. From Fig. 16, it is evident that westward traveling waves carry significantly less momentum than their eastward counterpart.

Superimposed onto the phase speed spectrum shown in Fig. 16 are two vertical dotted lines indicating the maximum storm-relative wind speeds, encountered above $z=30 \mathrm{~km}$, for the easterly QBO-phase simulation (at $-14 \mathrm{~m} \mathrm{~s}^{-1}$ ) and westerly QBO-phase simulation (at $31 \mathrm{~m} \mathrm{~s}^{-1}$ ). All eastward traveling waves with 
phase speeds less $31 \mathrm{~m} \mathrm{~s}^{-1}$ are dissipated before they pass through the shear layer in the westerly phase-QBO simulation. Similarly, all westward traveling waves with phase speeds less than $14 \mathrm{~m} \mathrm{~s}^{-1}$ are dissipated within the shear layer in the easterly phase-QBO simulation.

Let us now return to the question of whether the difference in the wave-induced mean-flow accelerations in the periodic-domain westerly and easterly phaseQBO simulations is due to differences in the amplitudes of the eastward and westward propagating waves or due to differences in the mean-state shear. Clearly the particular convective system that forces the gravity waves in these simulations generates an asymmetric response in which the strongest waves move toward the east. According to Fig. 16, it is also apparent that essentially all the momentum in the eastward moving waves is deposited in the lower stratosphere in the westerly phase simulation, but a significant fraction of the momentum in the westward moving waves can be transported through the easterly phase shear. An additional periodicdomain simulation (not shown) was performed in which the easterly phase winds were increased to $-21 \mathrm{~m} \mathrm{~s}^{-1}$, in which case most of the westward propagating waves are dissipated within the shear layer (not shown). This change in the mean stratospheric-shear layer produced only a small increase in the momentum-flux divergence and mean-flow deceleration relative to that already obtained with the weaker easterly phase shear.

Thus, it appears that the main reason for the asymmetry between the gravity wave momentum-flux divergence in the westerly and easterly phase-QBO simulations is due to the asymmetry of the forcing generated by our particular storm and not the characteristics of the QBO-shear layers themselves.

\section{The role of convectively triggered gravity waves in the QBO}

What do the preceding simulations suggest about the contribution of gravity wave-induced momentum fluxes to the total forcing for the QBO?

In order to link our results to the real atmosphere, we rely on the statistics of mesoscale convective systems (MCSs) compiled by Mohr and Zipser (1996), who used data collected by the Special Sensor Microwave/Imager (SSM/I) mounted on the Defense Meteorological Satellite Program (DMSP) F-11 satellite to classify the occurrence of MCSs between $35^{\circ} \mathrm{N}$ and $35^{\circ} \mathrm{S}$ based on their location, size, and intensity. As a measure of MCS intensity they used brightness temperature $\left(t_{b}\right)$ in the 85$\mathrm{GHz}$ band. It has been shown that the $85-\mathrm{GHz} t_{b}$ upwelling from a storm can be related to its microphysical characteristics and, at least in principal, to its intensity (Adler et al. 1991; Spencer et al. 1989; Adler et al. 1994).

Mohr and Zipser associated each MCS with one of 11 intensity classes according to the minimum $t_{b}$ recorded within the boundaries of the MCS (lower min- imum $t_{b}$ being associated with more intense MCSs). If we could associate our simulated MCS with one of Mohr and Zipser's intensity classes, we could estimate the average number of MCS at any given time that are as strong as the one in our simulations. Unfortunately, there is no simple and reliable way to associate the easily quantifiable characteristics of our simulated storm with the intensity classes defined by Mohr and Zipser. The $85-\mathrm{GHz} t_{b}$ is not sensible temperature. Nor is it necessarily even within $50-100 \mathrm{~K}$ of the sensible temperature (E. Zipser 1999, personal communication). A possibility would be to use a rainfall $-t_{b}$ relation such as $t_{b}$ $=251.0-2.09 R$, where $R$ is rainfall (measured in $\mathrm{mm}$ $\mathrm{h}^{-1}$ ), suggested by Adler et al. (1994), and obtain a hypothetical $t_{b}$ from our simulated rain rates. This method yields extreme uncertainties. The uncertainties are due to mainly two factors. First, the rainfall- $t_{b}$ relation is not very robust; the appropriate coefficient for the linear term varies by more than a factor 2 when the resolution in the rainfall data varies between 1.5 and 12 $\mathrm{km}$. This same coefficient varies by another factor 2 between oceanic and continental convection (Adler et al. 1994). Second, the estimate of a temporal average of maximum-rain rate for our simulation is extremely dependent on the spatial and temporal averaging intervals.

Real-world Hector events are certainly stronger than the average tropical MCS. However as discussed in section 2.2, the updrafts in our simulated storm are roughly half the strength of those observed during the merger phase of typical Hector events; in fact our storm is more representative of the much weaker mature phase of these events. Thus, in the absence of more quantitative guidance, we make a rough estimate that the simulated storm is representative of the average storm intensity in the Mohr and Zipser (1996) statistics. Nevertheless, our simulated storm is likely to be stronger, rather than weaker, than the average tropical MCS, so the following estimates might be best considered as upper bounds on the actual convectively generated gravity wave forcing.

The number of storms counted by Mohr and Zipser over a period of 4 months in the band between $15^{\circ} \mathrm{N}$ and $15^{\circ} \mathrm{S}$ band is 11707 , which suggests that 98 storms are present on average and that the average density of such storms is 1 per $1350000 \mathrm{~km}^{2}$. The ratio of this storm density to that in our simulation is $\sim 0.2$. Multiplying this ratio by the simulated mean flow acceleration, averaged over a $3-\mathrm{km}$ layer centered about the peak, we estimate the convectively triggered gravity wave forcing $\left(-\partial \overline{\rho u^{\prime} w^{\prime}} / \partial z\right)$ for the QBO to be up to $-0.12 \mathrm{~m} \mathrm{~s}^{-1} \mathrm{day}^{-1}$ for the westerly phase and up to $0.04 \mathrm{~m} \mathrm{~s}^{-1} \mathrm{day}^{-1}$ for the easterly phase.

The observed zonal accelerations in the shear zones of the QBO, averaged over the area equatorward of $\pm 15^{\circ}$ latitude, are on the order of $6 \mathrm{~m} \mathrm{~s}^{-1} \mathrm{month}^{-1}$ or $0.2 \mathrm{~m} \mathrm{~s}^{-1}$ day $^{-1}$ for the westerly phase and $-4 \mathrm{~m} \mathrm{~s}^{-1}$ month $^{-1}$ or $-0.13 \mathrm{~m} \mathrm{~s}^{-1}$ day $^{-1}$ for the easterly phase (Dunkerton and Delisi 1985). The forcing required to 
drive the QBO is twice the observed acceleration since the downward propagation of the QBO is opposed by the Brewer-Dobson circulation (Dunkerton 1997). Consequently, we estimate that convectively triggered gravity waves could account for up to $30 \%$ of the required forcing for the westerly QBO phase and up to $15 \%$ for the easterly QBO phase. Somewhat surprisingly, this result is comparable to that obtained by Alexander and Holton (1997) on the basis of 2D simulations.

\section{Summary and conclusions}

A 3D mesoscale model is used to study the dynamics and structure of convectively triggered gravity waves in the Tropics. The initial tropospheric sounding is taken to be representative of the environment over Bathurst and Melville Islands, north of Darwin, Australia, during a monsoon break period and just before a deep convective outbreak typical of that location (referred to as a "Hector"). The background tropospheric wind profile is representative of the climatology of the monsoon break periods for that region. Three stratospheric wind profiles are used. In the first case the stratospheric winds are constant with height. In the other two cases, the winds are representative of the easterly and westerly phases of the QBO.

In all three cases, the phase lines of the gravity waves triggered by the convection reveal an almost circularly symmetric structure as they enter the lower stratosphere. In the control case, bidimensional spectral analysis shows a peak in horizontal wavelength and in period of about $40 \mathrm{~km}$ and $35 \mathrm{~min}$, respectively, suggesting a peak in vertical wavelength of about $4-7 \mathrm{~km}$. Allowing for the factor of 2 difference in the static stability between the stratosphere and the troposphere, this preferred vertical wavelength appears to be associated with the vertical scale of the latent heating in the updraft cores. Spectral analysis also shows enhanced momentum flux associated with the gravity waves traveling in the direction opposite to the motion of the gust front.

In the QBO-wind shear cases, upward propagating gravity waves are effectively damped as they approach their critical layer. This damping is evident both in the bidimensional spectra and from direct observation of the 3D wave field. In the westerly QBO-phase case, the magnitude of the vertical momentum-flux divergence associated with critical-layer absorption peaks at $1 \mathrm{~m}$ $\mathrm{s}^{-1}$ day $^{-1}$. In the easterly QBO-phase case, it peaks at $0.3 \mathrm{~m} \mathrm{~s}^{-1} \mathrm{day}^{-1}$. The difference in vertical momentumflux divergence between the two phases appears to be due to the characteristics of the simulated MCS and not to our particular choice of QBO-shear profiles.

In the simulations with open lateral boundary conditions, the dynamical response to the wave-induced momentum-flux divergence is not simply a mean-flow acceleration that balances the momentum-flux divergence. Instead, a large cross-domain difference in the dynamic pressure is produced that is primarily balanced by a large mean-flow acceleration. The vertical momentum-flux divergence itself was a smaller term in the total momentum budget. These results are consistent with previous findings based on two-dimensional simulations of breaking mountain waves (Durran 1995). Although the fluid response to a localized region of gravity wave dissipation may be very nonlocal, there can be no cross-domain difference in the dynamic pressure in any horizontally periodic domain, such as the earth's atmosphere. In horizontally periodic domains, the wave-induced momentum-flux divergence must be primarily balanced by mean-flow acceleration. This was confirmed by a set of additional simulations that used periodic lateral boundaries. Although the mean-flow response was sensitive to the lateral boundary conditions, the forcing itself, that is, the gravity wave-induced momentum-flux divergence in the stratosphere, is almost identical in both the open- and periodic-domain simulations.

The results of our simulations were used together with climatological statistics of MCSs (Mohr and Zipser 1996) to estimate the forcing of the QBO due to convectively triggered gravity waves. We find that the momentum-flux divergence associated with convectively generated gravity waves could account for up to $30 \%$ of the forcing required for downward propagation of the westerly phase of the QBO, and up to $15 \%$ of the required forcing in the easterly phase of the QBO.

Acknowledgments. This research was sponsored by NSF Grant ATM-9322480 and NASA Grant NAG-12193. 
APPENDIX

Sounding Used to Initiate the Control Simulation

\begin{tabular}{|c|c|c|c|c|c|}
\hline $\begin{array}{l}z \\
\mathrm{~m}\end{array}$ & $\begin{array}{c}p \\
\mathrm{mb}\end{array}$ & $\begin{array}{c}\theta \\
K\end{array}$ & $\begin{array}{c}q \nu \\
\mathrm{g} \mathrm{kg}^{-1}\end{array}$ & $\begin{array}{c}u \\
\mathrm{~m} \mathrm{~s}^{-1}\end{array}$ & $\begin{array}{c}v \\
\mathrm{~m} \mathrm{~s}^{-1}\end{array}$ \\
\hline 1 & 1010 & 306.0 & 22.5 & -0.6 & 0.0 \\
\hline 89 & 1001 & 305.8 & 20.5 & -1.0 & 0.0 \\
\hline 200 & 988 & 305.5 & 20.5 & -1.5 & 0.0 \\
\hline 546 & 950 & 305.3 & 20.5 & -2.3 & 0.0 \\
\hline 1022 & 899 & 306.0 & 14.0 & -5.0 & 0.0 \\
\hline 1517 & 849 & 306.3 & 12.5 & -7.6 & 0.0 \\
\hline 2036 & 798 & 319.0 & 11.5 & -8.8 & 0.0 \\
\hline 2582 & 748 & 311.5 & 7.3 & -9.6 & 0.0 \\
\hline 3159 & 698 & 314.4 & 4.3 & -11.5 & 0.0 \\
\hline 3772 & 648 & 317.2 & 6.0 & -9.6 & 0.0 \\
\hline 4425 & 598 & 320.7 & 3.5 & -8.7 & 0.0 \\
\hline 5126 & 548 & 325.0 & 2.6 & -6.6 & 0.0 \\
\hline 5882 & 498 & 328.5 & 1.9 & -5.5 & 0.0 \\
\hline 6705 & 448 & 333.6 & 1.3 & -3.9 & 0.0 \\
\hline 7608 & 398 & 337.2 & 0.80 & -2.7 & 0.0 \\
\hline 8605 & 348 & 340.9 & 0.45 & -2.4 & 0.0 \\
\hline 9720 & 294 & 344.3 & 0.17 & -2.0 & 0.0 \\
\hline 10997 & 248 & 350.1 & 0.07 & -2.0 & 0.0 \\
\hline 12479 & 199 & 354.7 & 0.01 & -2.0 & 0.0 \\
\hline 13330 & 174 & 356.1 & 0.0 & -2.3 & 0.0 \\
\hline 14278 & 149 & 360.6 & 0.0 & -2.8 & 0.0 \\
\hline 15356 & 124 & 367.0 & 0.0 & -4.5 & 0.0 \\
\hline 16625 & 99.0 & 369.1 & 0.0 & -6.0 & 0.0 \\
\hline 17000 & 92.4 & 388.6 & 0.0 & -7.0 & 0.0 \\
\hline 18000 & 76.8 & 409.2 & 0.0 & -8.0 & 0.0 \\
\hline 19000 & 63.7 & 430.9 & 0.0 & -9.0 & 0.0 \\
\hline 20000 & 52.7 & 453.7 & 0.0 & -9.0 & 0.0 \\
\hline 22500 & 32.5 & 516.3 & 0.0 & -9.0 & 0.0 \\
\hline 25000 & 19.5 & 634.2 & 0.0 & -9.0 & 0.0 \\
\hline 27500 & 11.3 & 721.3 & 0.0 & -9.0 & 0.0 \\
\hline 30000 & 6.36 & 820.4 & 0.0 & -9.0 & 0.0 \\
\hline 32500 & 3.41 & 933.1 & 0.0 & -9.0 & 0.0 \\
\hline 35000 & 1.73 & 1061.2 & 0.0 & -9.0 & 0.0 \\
\hline 37500 & 0.809 & 1207.0 & 0.0 & -9.0 & 0.0 \\
\hline 40000 & 0.335 & 1372.7 & 0.0 & -9.0 & 0.0 \\
\hline 42500 & 0.113 & 1561.3 & 0.0 & -9.0 & 0.0 \\
\hline
\end{tabular}

\section{REFERENCES}

Adler, R. F., H.-Y. Yeh, N. Prasad, W.-K. Tao, and J. Simpson, 1991: Microwave simulations of a tropical rainfall system with a threedimensional cloud model. J. Appl. Meteor., 30, 924-953.

— , G. J. Huffman, and P. R. Keehn, 1994: Global tropical rain estimates from microwave-adjusted geosynchronous IR data. $R e-$ mote Sens. Rev., 11, 125-152.

Alexander, M., and L. Pfister, 1995: Gravity wave momentum flux in the lower stratosphere over convection. Geophys. Res. Lett., 22, 2029-2032.

—, and J. Holton, 1997: A model study of zonal forcing in the equatorial stratosphere by convectively induced gravity waves. J. Atmos. Sci., 54, 408-419.

—,$\ldots$, and D. Durran, 1995: The gravity wave response above deep convection in a sqall line simulation. J. Atmos. Sci., 52, 2212-2226.

Dewan, E., R. Picard, R. O'Neil, H. Gardiner, J. Mill, E. Richards, M. Kendra, and W. Gallery, 1998: MSX satellite observation of thunderstorms-generated gravity waves in the mid-wave infrared images of the upper stratosphere. Geophys. Res. Lett., 25, 939942.

Dunkerton, T., 1997: The role of gravity waves in the quasi-biennial oscillation. J. Geophys. Res., 102, $26053-26076$.

- , and D. Delisi, 1985: Climatology of the lower equatorial stratosphere. J. Atmos. Sci., 42, 376-396.

Durran, D. R., 1995: Do breaking mountain waves decelerate the mean flow? J. Atmos. Sci., 52, 4010-4032.

- 1999: Numerical Methods for Wave Equations in Geophysical Fluid Dynamics. Texts in Applied Mathematics Series, Vol. 32, Springer, $465 \mathrm{pp}$.

—, and J. Klemp, 1983: A compressible model for the simulation of moist mountain waves. Mon. Wea. Rev., 111, 2341-2361.

Elliassen, A., and E. Palm, 1960: On the transfer of energy in stationary mountain waves. Geofys. Publ., 3, 1-23.

Fovell, R., D. Durran, and J. Holton, 1992: Numerical simulations of convectively generated gravity waves. J. Atmos. Sci., 49, $1427-1442$.

Hauf, T., and T. Clark, 1989: Three-dimensional numerical experiments on convectively forced internal gravity waves. Quart. J. Roy. Meteor. Soc., 115, 309-333.

Keenan, T., and R. Carbone, 1992: A preliminary morphology of precipitation systems in tropical northern Australia. Quart. J. Roy. Meteor. Soc., 118, 283-326.

— B B. Ferrier, and J. Simpson, 1994: Development and stucture of a maritime continent thunderstorm. Meteor. Atmos. Phys., 53, $185-222$.

Kershaw, R., 1995: Parametrization of momentum transport by convectively generated gravity waves. Quart. J. Roy. Meteor. Soc., 121, 1023-1040.

Lane, T. P., M. J. Reeder, and T. L. Clark, 2000: Numerical modeling of gravity wave generation by deep tropical convection. J. Atmos. Sci., in press.

Larsen, M., W. Swartz, and R. Woodman, 1982: Gravity-wave generation by thunderstorms observed with a vertically pointing 430 MHz radar. Geophys. Res. Lett., 9, 571-574.

McFarlane, N., 1987: The effect of orographically exited gravity wave drag on the general circulation of the lower stratosphere and troposphere. J. Atmos. Sci., 44, 1775-1800.

Mohr, K. I., and E. J. Zipser, 1996: Mesoscale convective systems defined by their $85-\mathrm{GHz}$ ice scattering signature: Size and intensity comparison over tropical oceans and continents. Mon. Wea. Rev., 124, 2417-2437.

Pandya, R., D. Durran, and C. Bretherton, 1993: Comments on "Thermally forced gravity waves in an atmosphere at rest." J. Atmos. Sci., 50, 4097-4101.

Salby, M., and R. Garcia, 1987: Transient response to localized episodic heating in the Tropics. Part I: Excitation and short-time near-field behavior. J. Atmos. Sci., 44, 458-498.

Simpson, J., T. Keenan, B. Ferrier, R. Simpson, and G. Holland, 1993: Cumulus mergers in the maritime continent region. Meteor. Atmos. Phys., 51, 73-99.

Skamarock, W., and J. Klemp, 1993: Adaptive grid refinement for two-dimensional and three-dimensional nonhydrostatic atmospheric flow. Mon. Wea. Rev., 121, 788-804.

Spencer, R. W., H. M. Goodman, and R. E. Hood, 1989: Precipitation retrieval over land and ocean with the SSM/I: Identification and characteristics of scattering signal. J. Atmos. Oceanic Technol., 6, 254-273. 